\title{
EDITORIAL
}

\section{Pharmacogenomic testing and antidepressant response: problems and promises}

\author{
Tawny L. Smith, (iD Charles B. Nemeroff (iD \\ University of Texas at Austin Dell Medical School, Austin, TX, USA.
}

Because there are several disease entities for which multiple medications have been approved by regulatory agencies such as the FDA, clinicians must decide which medication is optimal for any given patient. Without any way to predict treatment response a priori, clinicians are left with the practice of trial and error, and frequently experience a delay in finding an effective treatment. This has led to the burgeoning field of personalized medicine to predict pharmacologic treatment. Genetic variations have been hypothesized to be one of the major contributors to individual differences seen in drug response, as well as in side-effect liability.

Over the past decade, interest in the field of pharmacogenomics (PGX) has expanded exponentially. Our oncology colleagues have experienced the most rapid advances in incorporating PGx into personalized medicine. Interest in incorporating PGx into psychiatry is derived from our clinical understanding that some patients respond to some medications but not to others, e.g., in depression. This has led our field to attempt to identify genetic markers to predict treatment response as well as side effects. Unfortunately, genome-wide association studies (GWAS) of antidepressant response have yet to consistently replicate any individual single-nucleotide polymorphisms (SNPs) that meet genome-wide significance. $^{1}$

The International Society of Psychiatric Genetics (ISPG) updated their policy statement on genetic testing in psychiatry in early 2019 . $^{2}$ They emphasize that PGX testing is a clinical-support tool to be used in conjunction with good clinical decision making. Considerable emphasis has been placed on certain cytochrome P450 isoenzymes, because several antidepressants are either substrates or inhibitors of these. However, ISPG does not encourage the widespread use of $P G x$, suggesting that genetic testing for CYP2C19 and CYP2D6 would be most beneficial in patients who have "experienced inadequate response or adverse reactions to a previous antidepressant" and encouraging clinicians to utilize data available in FDA labeling and Clinical Pharmacogenetics Implementation Consortium (CPIC) guidelines. ${ }^{2}$ CPIC TCA and SSRI dosing guidelines, ISPG, and FDA labeling all focus solely on CYP2C19 and CYP2D6 polymorphisms and on the metabolism of certain antidepressants. ${ }^{2-4}$

Correspondence: Charles B. Nemeroff, 1601 Trinity Street, Stop Z0600, 78712, Austin, TX, USA.

E-mail: cnemeroff@austin.utexas.edu

Submitted Nov 25 2019, accepted Dec 012019.
Other thought leaders and experts in the area concur with these recommendations. ${ }^{5}$

Despite guideline recommendations and expert opinions, over 35 commercial entities provide combinatorial PGx testing for depression in the United States, with claims of predicting antidepressant response and tolerability based on an individual's pharmacokinetic and pharmacodynamics gene variants. Interestingly, the largest randomized controlled trial (RCT), the GUIDED study, was unable to predict antidepressant tolerability despite including CYP2D6 and CYP2C19 polymorphisms. ${ }^{6}$ Candidate gene polymorphisms selected to predict efficacy, such as the serotonin transporter and serotonin receptors, have also not been informative. There has been much debate about the clinical utility and validity of this testing, and the conclusion of both a meta-analysis and expert opinion is that there is insufficient evidence that any of these tests can predict either antidepressant efficacy or tolerability. ${ }^{2,6}$

However, a recent meta-analysis of five RCTs demonstrated that, overall, individuals with PGx-guided antidepressant treatment were 1.7 times more likely to achieve remission than usual care. ${ }^{6}$ At face value, this seems promising. However, there are several concerns with this conclusion. First, remission of symptoms was not the primary outcome measure in any of the studies, and the GUIDED study ${ }^{7}$ failed to meet its primary outcome. Also, the population included in the meta-analysis was composed predominately of white women aged 40-50 years. Many patients do not fit this description, which leads us to question the generalizability of the studies. Additionally, the meta-analysis was unable to inform us at what point in antidepressant treatment PGx testing is most beneficial. As a whole, the five studies have also been criticized because of a lack of transparency in their algorithms and a lack of blinding in most of the studies.

One of the criticisms of universal PGx testing to predict antidepressant response is the variability in the gene variants comprising each company's panel. Of the four companies that have published RCTs of PGx-guided treatment versus usual care, each company tests for a different panel of pharmacokinetic and pharmacodynamic candidate genes and SNPs. ${ }^{8}$ These differences lead to varying antidepressant recommendations in the proprietary

How to cite this article: Smith TL, Nemeroff CB. Pharmacogenomic testing and antidepressant response: problems and promises. Braz J Psychiatry. 2020;42:116-117. http://dx.doi.org/10.1590/1516-44462019-0799 
PGx report. Therefore, a positive finding in one study does not indicate that all pharmacogenetic testing is useful. Unfortunately, no head-to-head trials of different PGx testing platforms have been conducted, so we have no idea whether any one company yields superior results.

At the end of 2018, the FDA issued a safety communication statement cautioning clinicians and patients that the majority of PGx testing platforms have not been FDAapproved, indicating that most genetic tests lack clinical evidence to support their use to predict response to a specific medication. ${ }^{9}$ The FDA safety communication also stated: "Changing drug treatment based on the results from such a genetic test could lead to inappropriate treatment decisions and potentially serious health consequences for the patient." The statement also goes on to warn genetic test manufacturers and developers that, if their test claims to predict a patient's response to specific medications, they should make sure that recommendations are in agreement with FDA-approved labeling. ${ }^{9}$ Since issuing the statement, the FDA has reached out to several PGx companies which market their tests with claims to predict how a person may respond to a specific medication. Many - but not all companies have addressed the FDA's concerns by removing specific names of medications from their promotional materials, as well as from patient test reports.

The field of PGx is advancing quickly, but evidence of its utility is meager. There is clearly insufficient evidence to support the universal use of $P G x$ testing to guide antidepressant treatment decisions. Of course, gene structure is only one piece of the puzzle that contributes to inter-individuality of antidepressant response. Personal or environmental variables, such as concomitant medications, ethnicity, gender, smoking status, and comorbidities, are important as well. We are hopeful that future research with candidate genes such as the corticotropinreleasing hormone binding protein, norepinephrine transporter, and FKBPs, as well as inflammatory biomarkers and epigenetics, will lead to platforms with clinical utility for predicting antidepressant response. ${ }^{10,11}$

\section{Acknowledgements}

CBN has received research grants from the National Institutes of Health (NIH); has served in the scientific advisory boards of the American Foundation for Suicide Prevention (AFSP), Brain and Behavior Research Foundation (BBRF), Anxiety Disorders Association of America (ADAA), Skyland Trail, and Laureate Institute for Brain Research (LIBR).

\section{Disclosure}

CBN has served as a consultant for Xhale, Takeda, Taisho Pharmaceutical Inc., Signant Health, Sunovion
Pharmaceuticals Inc., Janssen Research \& Development LLC, Magstim Inc., Navitor Pharmaceuticals Inc., TC MSO Inc., Intra-Cellular Therapies Inc., EMA Wellness, Gerson Lehrman Group (GLG), and Acadia Pharmaceuticals; is a stockholder in Xhale, Celgene, Seattle Genetics, Abbvie, OPKO Health Inc., Antares, BI Gen Holdings Inc., Corcept Therapeutics Pharmaceuticals Company, TC MSO Inc., Trends in Pharma Development, LLC, and EMA Wellness; and has served in the scientific advisory boards of Xhale and Signant Health. The other author reports no conflicts of interest.

\section{References}

1 Corponi F, Fabbri C, Serretti A. Pharmacogenetics and depression: a critical perspective. Psychiatr Investig. 2019;16:645-53.

2 International Society for Psychiatric Genetics (ISPG). Genetic testing statement: genetic testing and psychiatric disorders: a statement from the International Society of Psychiatric Genetics [Internet]. 2019 Mar 11 [cited 2019 Sep 30]. ispg.net/genetic-test ing-statement/

3 Hicks JK, Sangkuhl K, Swen JJ, Ellingrod VL, Müller DJ, Shimoda K, et al. Clinical Pharmacogenetics Implementation Consortium guideline (CPIC) for CYP2D6 and CYP2C19 genotypes and dosing of tricyclic antidepressants: 2016 update. Clin Pharmacol Ther. 2017;102:37-44.

4 Hicks JK, Bishop JR, Sangkuhl K, Müller DJ, Ji Y, Leckband SG, et al. Clinical Pharmacogenetics Implementation Consortium (CPIC) guideline for CYP2D6 and CYP2C19 genotypes and dosing of selective serotonin reuptake inhibitors. Clin Pharmacol Ther. 2015;98: 127-34.

5 Zeier Z, Carpenter LL, Kalin NH, Rodriguez Cl, McDonald WM, Widge AS, et al. Clinical implementation of pharmacogenetic decision support tools for antidepressant drug prescribing. Am J Psychiatry. 2018;175:873-86

6 Bousman CA, Arandjelovic K, Mancuso SG, Eyure HA, Dunlop BW. Pharmacogenetic tests and depression symptom remission: a metaanalysis of randomized controlled trials. Pharmacogenomics. 2019;20: 37-47.

7 Greden JF, Parikh SV, Rothschild AJ, Thase ME, Dunlop BW, DeBattista C, et al. Impact of pharmacogenomics on clinical outcomes in major depressive disorder in the GUIDED trial: a large, patient- and rater-blinded, randomized, controlled study. J Psychiatr Res. 2019;111:59-67.

8 Bousman CA, Dunlop BW. Genotype, phenotype, and medication recommendation agreement among commercial pharmacogeneticbased decision support tools. Pharmacogenomics J. 2018;18: 613-22.

9 U.S. Food and Drug Administration (FDA). The FDA warns against the use of many genetic tests with unapproved claims to predict patient response to specific medications: FDA Safety Communication [Internet]. 2018 Oct 31 [cited 2019 Sep 30]. fda.gov/ medical-devices/safety-communications/fda-warns-against-usemany-genetic-tests-unapproved-claims-predict-patient-responsespecific

10 O'Connell CP, Goldstein-Piekarski AN, Nemeroff CB, Schatzberg AF, Debattista C, Carrillo-Roa T, et al. Antidepressant outcomes predicted by genetic variation in corticotropin-releasing hormone binding protein. Am J Psychiatry. 2018;175:251-61.

11 Hack LM, Fries GR, Eyre HA, Bousman CA, Singh AB, Quevedo J, et al. Moving pharmacoepigenetics tools for depression toward clinical use. J Affect Disord. 2019;249:336-46. 